\title{
Antiproliferative Effect of Mesenchymal Stem Cells on Human Breast Carcinoma: New Insight on FOXO/IncRNA-AF085935 Axis
}

\author{
Sahar H. Ahmed ${ }^{1}$, Abeer Mostafa ${ }^{2 *} \mathbb{D}$, Amany A. Abou-Elalla ${ }^{1} \mathbb{D}$
}

${ }^{1}$ Department of Medical Laboratory Technology, Faculty of Applied Health Science Technology, Misr University for Science and Technology, 6th of October City, Egypt; ${ }^{2}$ Department of Medical Biochemistry and Molecular Biology, Faculty of Medicine, Cairo University, Cairo, Egypt

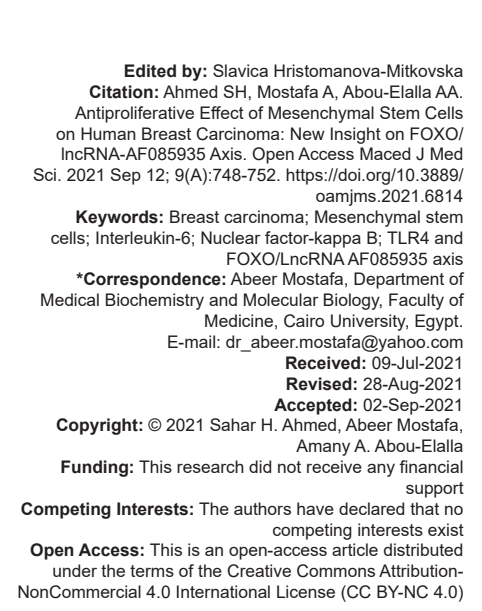

\section{Abstract}

AIM: Cancer breast is one of the most common cancers in women leading to death; that is why we are in urgent need to develop new modalities of treatment. Mesenchymal stem cells (MSCs) have an anti-inflammatory effect due to capability to regenerate the damaged tissues.

METHODS: MCF7 breast cancer cells were divided into two groups; group 1: untreated cancer cells, group 2 cancer cells cocultured with MSCs; after 24 incubation the cells from the two groups were collected to assess cell proliferation, Interleukin-6 (IL-6) levels and genes expression of Nuclear factor-kappa B (NF-KB), FOXO, and LncRNA AF085935.

RESULTS: Statistically significant decrease in cancer cell proliferation and all other studied parameters in cancer cells after coculture with MSCs.

CONCLUSION: Breast carcinoma once initiated; it runs in a vicious circle due to stimulation of FOXO/LncRNA AF085935 axis by the inflammatory mediators released from cancer environment. FOXO/LncRNAAF085935 induces cancer proliferation and survival; furthermore, FOXO once induced, it produces further induction of inflammatory cytokines IL-6 and NF-KB and so on, MSCs due to its anti-inflammatory role could break this circle and thus inhibit cancer cell proliferation.

Graphical abstract

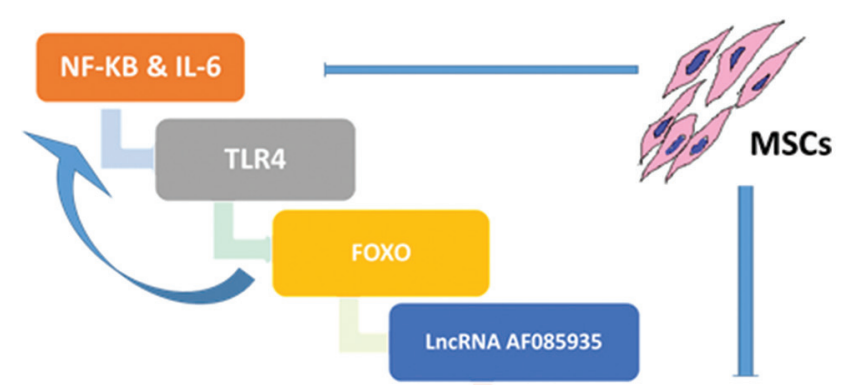

Cancer cell

proliferation

\section{Introduction}

Breast carcinoma is one of the leading causes of cancer death in women. Recently approved that there is a strong relation between inflammation and breast cancer [1].

Toll-like receptors (TLRs) are key receptors in innate immunity and inflammation. TLRs in addition expressed in different cancer cells. Recent evidence suggests that TLRs play an important role in cancer initiation and progression [2]. TLRs are stimulated by endogenous danger-associated molecular patterns
(DAMPs), which are released in cancer development followed by successive stimulation of inflammatory pathways [3].

NF-k $\beta$ is an important tumor-promoting transcription factor. TLRs signaling can intrinsically and extrinsically upregulate the inflammatory cytokines such as interleukin-6 (IL-6), IL-1b, and tumor necrosis factor a (TNF-a) through NF-k $\beta$-dependent pathways [4].

TLR signaling has also been shown to regulate cell death and increase the expression of the antiapoptotic proteins. In addition, TLR4 signaling induces tumor escape from the immune system and enhances tumor cell metastasis [5]. 
Forkhead box (FOX) proteins are a superfamily of transcriptional regulators, that control a wide range of biological processes, therefore, a disturbance of Fox activity can alter cell development, initiate tumorogenesis and cancer metastasis [6].

Long non-coding ribonucleic acids (LncRNAs) are non-coding RNAs, shorter than 200 nucleotides in length. Several IncRNAs are involved in crucial signaling pathways of tumorigenesis. Such as IncRNA-AF085935 [7], [8].

Mesenchymal stem cells (MSCs) are progenitor cells, which can be isolated from different types of tissues like bone marrow, adipose tissue, umbilical cord. MSCs process a tropism to damaged tissues and tumor sites makes them a promising agent in cancer therapy [9].

\section{Materials and Methods}

\section{Human umbilical cord MSCs isolation}

Human umbilical cord specimens were obtained after approval of the ethical committee of faculty of Medicine. MSCs were isolated by collagenase II enzyme (IgG, C. histoliticum, Biological life science, USA), digested and maintained in $2 \%$ fetal bovine serum (FBS) and 1× Pen/Strep (Invitrogen, CA, USA). Cells were incubated at $5 \% \mathrm{CO}_{2}, 37^{\circ} \mathrm{C}$ until cells will reach $70 \%-80 \%$ confluency, then trypsinized with $0.25 \%$ trypsin for $5 \mathrm{~min}$ at $37^{\circ} \mathrm{C}$. After centrifugation, cell pellets were resuspended with medium for further coculture with MCF7 cancer cells [10].

\section{MCF7 cancer cells isolation}

Human breast adenocarcinoma (MCF7) cells were obtained from (VACSERA, Egypt). The cells were grown in Dulbecco's modified Eagle's medium supplemented with $10 \%$ FBS and antibiotics $(100 \mathrm{U} / \mathrm{mL}$ penicillin and $100 \mu \mathrm{g} / \mathrm{mL}$ streptomycin) in $5 \% \mathrm{CO} 2$ at $37^{\circ} \mathrm{C}$. By day 3 , cells were trypsinized, centrifuged and resuspended with fresh medium.

\section{hucMSCs}

\section{Coculture of MCF7 cancer cells and}

MCF7 cancer cells were divided in 96 well plate for 3-[4, 5-dimethylthiazol-2yl]-2, 5- diphenyltetrazolium bromide (MTT) assay and two culture flasks for molecular studies then coculterd with MSCs incubated for $24 \mathrm{hrs}$

\section{Cells proliferation MTT assay}

The measurement of cell proliferation was done by MTT cell proliferation kit (Trevigen Inc., Wiesbaden-Nordenstadt, Germany). MCF7cancer cells were seeded in 96-well microtiter plates at the required concentration of $1 \times 10^{4}$ cells/well and after overnight incubation half of plate was cocultured with $1 \times 10^{4}$ MSCs. After $24 \mathrm{~h}$ cells incubation, $10 \mathrm{~mL}$ of tetrazolium compound, MTT was added to the wells and the cells were incubated $2-4 \mathrm{~h}$ at $37^{\circ} \mathrm{C}$. MTT was reduced by metabolically active cells to insoluble purple formazan dye crystals. When purple precipitate was clearly visible under the microscope, $100 \mathrm{~mL}$ of detergent reagent was added to all wells. The covered plate was left in the dark at $18-24^{\circ} \mathrm{C}$ for overnight. the absorbance was measured at $570 \mathrm{~nm}$ with a reference wavelength of $650 \mathrm{~nm}$. Cell proliferation was assessed as the percentage of cell proliferation compared to untreated MCF7 as control cells.

IL-6 estimation from culture medium by ELISA techniqe: IL-6 level was detected according to kit instructions (Invitrogen Corporation, Camarillo, CA, USA).

IncRNA-AF085935, TLR4, Nuclear factorkappa $B$ (NF-KB) and FOXO genes expression by quantitative reverse transcription polymerase chain reaction (qRT PCR)

\section{Isolation of total RNA}

Total RNA was extracted from the two studied groups by RNA isolation system (Promega, Madison, $\mathrm{WI}$ ).

Table 1: primers sequence for studied genes

\begin{tabular}{ll}
\hline TLR4 & Forward primer: TGGATACGTTTCCTTATAAG \\
& Reverse primer: GAAATGGAGGCACCCCTTC 18S \\
NF-KB & Forward primer: TACCATGCTCTTTTGGTTAC \\
& Reverse primer: TCCCTCTTTTTCTATTGATTGGA \\
FOXO & Forward primer: TGCATCCATGGACAACAACA \\
& Reverse primer: CGAGGGCGAATGTACTCCAGTT \\
InCRNA-AF085935 & Forward primer: CAGGGCAGCAAGGTGTTTC \\
& Reverse primer: TTGGTGGGTGCCTGATACC \\
\hline
\end{tabular}

\section{One step RT PCR}

$5 \mu \mathrm{L}$ of extracted RNA were added to qRTPCR SYBR ${ }^{\mathrm{TM}}$ green master mix (Abgene, Hamburg, Germany) and the appropriate primers (Table 1) then filled with deionized water to $25 \mu \mathrm{L}$. qRT-PCRs in an Applied Biosystems Step One ${ }^{\mathrm{TM}}$ RT-PCR system (Applied Biosystems, Foster City, CA, USA) with 2 min as initial stage at $50^{\circ} \mathrm{C}$ to activate the DNA polymerase, followed by 40 cycles of $95^{\circ} \mathrm{C}$ for $15 \mathrm{~s}, 60^{\circ} \mathrm{C}$ for $1 \mathrm{~min}$ and $72^{\circ} \mathrm{C}$ for $1 \mathrm{~min} . \Delta \Delta \mathrm{Ct}$ were calculated from: $\Delta \Delta \mathrm{Ct}$ $=\Delta \mathrm{CT}$ sample assessed gene (CT sample assessed gene-CT reference home gene GAPDH (glycerol aldehyde phosphate dehydrogenase)) $-\Delta C T$ calibrator 
(CT control gene- CT reference home gene GAPDH). Then, $2-\Delta \Delta \mathrm{Ct}$ gives the relative quantification gene expression compared to the control; Standardization was performed by quantification of the GAPDH gene as an endogenous control.

Table 2: correlation between studied parameters

\begin{tabular}{|c|c|c|c|c|c|c|}
\hline & NFKB & IL6 & TLR4 & FOXO & AF085935 & Cell proliferation \\
\hline \multicolumn{7}{|l|}{ NFKB } \\
\hline $\mathrm{r}$ & 1 & $.961^{\star *}$ & $.948^{* *}$ & $.947^{\star \star}$ & $.911^{* *}$ & $.939 * *$ \\
\hline \multirow{2}{*}{\multicolumn{7}{|c|}{$<0.001<-0.001 \quad 0.002$}} \\
\hline & & & & & & \\
\hline$r$ & $.961^{* \star}$ & 1 & $.876^{* *}$ & $.950^{\star \star}$ & $.969^{* *}$ & $.897^{\star *}$ \\
\hline$p$ value & $<0.001$ & & 0.004 & $<0.001$ & $<0.001$ & 0.003 \\
\hline \multicolumn{7}{|l|}{ TLR4 } \\
\hline $\mathrm{r}$ & $.948^{\star *}$ & $.876^{\star \star}$ & 1 & $.880^{\star \star}$ & $.813^{*}$ & $.837^{\star *}$ \\
\hline$p$ value & $<0.001$ & 0.004 & & 0.004 & 0.014 & 0.01 \\
\hline \multicolumn{7}{|l|}{ FOXO } \\
\hline $\mathrm{r}$ & $.947^{\star \star}$ & $.950^{* *}$ & $.880^{\star *}$ & 1 & $.962^{\star \star}$ & $.894^{\star *}$ \\
\hline \multirow{2}{*}{\multicolumn{7}{|c|}{ AF085935 }} \\
\hline & & & & & & \\
\hline$r$ & $.911^{\star *}$ & $.969^{* *}$ & $.813^{*}$ & $.962^{\star \star}$ & 1 & $.836^{* *}$ \\
\hline$p$ value & 0.002 & $<0.001$ & 0.014 & $<0.001$ & & 0.01 \\
\hline \multicolumn{7}{|c|}{ Cell proliferation } \\
\hline $\mathrm{r}$ & $.939^{* *}$ & $.897^{* *}$ & $.837^{* *}$ & $.894^{\star \star}$ & $.836^{* *}$ & 1 \\
\hline$p$ value & 0.001 & 0.003 & 0.01 & 0.003 & 0.01 & \\
\hline
\end{tabular}

* Correlation is significant at the 0.01 level (2-tailed).

Cancer cell proliferation is significantly correlated with inflammatory markers IL-6, NFKB, TLR4 (P value= $0.003,0.001,0.01),(r=0.897,0.939,0.0 .837)$ respectively ; all previous markers are significantly correlated with FOXO and InCRNA-AF085935 ( $p$ value $<0.001$ ); cancer cell proliferation is significantly correlated with FOXO and IncRNA-AF085935( $\mathrm{p}$ value $=0.003,0.01)(\mathrm{r}=0.894,0.836$ ) respectively.

\section{Statistical analysis}

Data were coded as mean and standard deviation and analyzed by SPSS software. Paired sample t-test was used to compare between untreated cancer cells and cancer cells cocultured with MSCs. Persons correlation was done to detect the correlation between studied parameters. $p<0.05$ is considered significant (Table 2).

\section{Result}

\section{Coculture of MCF7 and MSCs}

MSCs were identified by their spindle shape that then form clusters attacking cancer cells with marked reduction in a number of cancer cells (Figure 1).

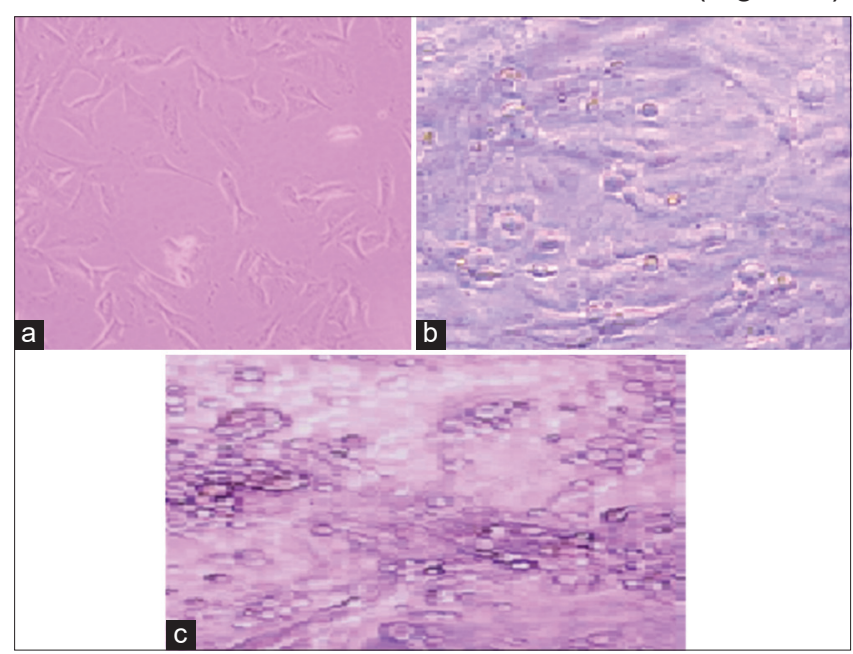

Figure 1: (a) Spindle-shaped MSCs (b) MCF7 cancer cells (c) coculture of both MCF7 cancer cells and MSCs showing cluster of MSCs around MCF7 with marked decrease in number of cancer cells

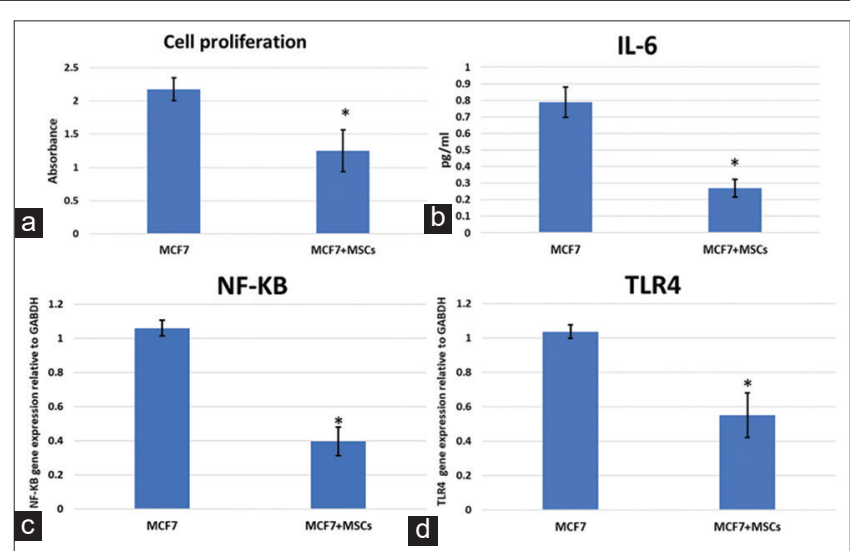

Figure 2: Significant decrease in cell proliferation and inflammatory markers IL6, NF-KB, and TLR4 after coculture of MCF7 with MSCs $(p<0.05)$

\section{proliferation}

\section{MSCs significantly inhibits cancer cells}

Statistically significant decrease in proliferation of cancer cells cocultured with MSCs compared to untreated cancer cells $(p=0.016)$ (Figure 2a)

\section{MSCS inhibit the inflammation in tumor environment}

Statistically significant decrease in IL6 level in the media derived from cultured cancer cells with MSCs compared to untreated cells $(p=0.004)$ (Figure $2 b)$, and downregulation of inflammatory genes NF-KB, TLR4 ( $p=0.002,0.008)$ (Figure 2c and d).

\section{FOXO gene and IncRNA-AF085935 are} downregulated in MSCs treated cancer cells

Statistically significant decrease in the expression of FOXO gene and IncRNA-AF085935 in MCF7 cocultured with MSCs compared to untreated cells ( $p=$ $0.005,0.009$ respectively) (Figure $3 a$ and $b$ )

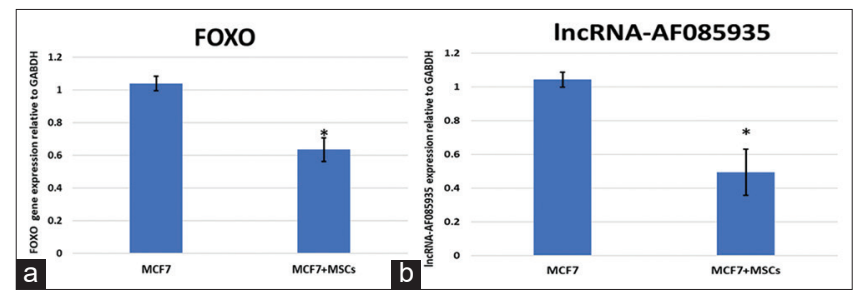

Figure 3: Significant decrease in FOXO gene and IncRNA-AF085935 expression after coculture of MCF7 with MSCs $(p<0.05)$

\section{Cancer cell proliferation significantly correlated with inflammatory markers, FOXO and IncRNA-AF085935}

Cancer cell proliferation is significantly correlated with inflammatory markers IL-6, NFKB, TLR4 ( $p=0.003$, $0.001,0.01),(r=0.897,0.939,0.0 .837)$ respectively; all previous markers are significantly correlated with FOXO and IncRNA-AF085935 ( $p<0.001$ ); cancer cell proliferation is significantly correlated with FOXO and 
IncRNA-AF085935( $p=0.003,0.01)(r=0.894,0.836)$ respectively.

\section{Discussion}

Breast cancers represent a major health risk for women throughout the world. Previous researches reported a significant relation of chronic inflammation at the local and/or systemic level in breast tumor pathobiology. Inflammation could induce breast cancer progression, metastasis through a variety of cytokines and hormones This provides a novel area for the development of new strategies for prevention [11].

IL-6 is a pleiotropic cytokine that plays a crucial role in regulating the inflammatory process [12]. $\mathrm{NF}-\kappa \mathrm{B}$ is an inflammatory cytokines that plays a role in human cancer initiation, development, metastasis, and resistance to treatment [13].

hMSC are undifferentiated cells capable of selfrenewal and proliferation; Due to their ability to migrate, hMSCs have an anti-inflammatory role and re-creation of tissue integrity. Inflammation and tissue damage are strong chemoattractants for hMSC, Cancer tissue release inflammatory cytokine as inflamed tissue; hence, there is a strong tropism of hMSC towards tumors [14] in this study we found significant decrease in inflammatory markers IL6 and NFKB in cancer cells treated by MSCs; it could be due to the inflammatory effect of MSCs. We aimed in this study to detect the molecular mechanism by which MSCs inhibit cancer cells proliferation; as we found significant decrease in cell proliferation in cancer cells cocultured with MSCs compared to untreated cells.

TLRs play a role in both breast cancer cells and the microenvironment. TLRs are mainly expressed in macrophages, dendritic cells, and other innate immune cells [15]. In coincide to previous studies; we found that TLRs are highly expressed in breast cancer cells. It has been suggested that NF-k $\beta$ induces TLR activation that promotes tumor cell survival in several types of cancer [16]. TLR signaling can promote tumor progression and immune evasion in addition to resistance of tumor cells to cell death [17]. We found significant decrease in TLR4 expression in cultured cancer cells with MSCs compared to untreated cells; thus we could say that TLR4 is the effector of inflammatory cytokines such as IL6 and NF-KB; furthermore due to the antiinflammatory effect of MSCs could block the stimulation of TLR4, thus breast cancer cells could not survive and proliferate; but the question now is there is another molecular mediators are involved in the mechanism by which MSCs inhibit cancer cells proliferation; based on previous studies that investigated factors that control cancer cell proliferation we found that FOXO/IncRNA AF085935 axis is one of the major pathways that control cancer cell survival [18]. We found that FOXO/ IncRNA AF085935 are highly expressed in cancer cells but after coculture with MSCs we found downregulation of $\mathrm{FOXO/IncRNA} \mathrm{AF085935,} \mathrm{but} \mathrm{the} \mathrm{question} \mathrm{now} \mathrm{is}$ there is a relation between FOXO/IncRNA AF085935 and TLR4? In this study, we found significant correlation between TL4 and both FOXO/IncRNA AF085935.

The transcriptional factor $\mathrm{FoxO}$ is a key regulator of cell metabolism, cell cycle, and cell death. Previous study reported that FoxO can promote inflammation by enhancing TLR4 signaling [19], furthermore; another study reported that Foxo up-regulates the expression of inflammatory cytokines IL-6 [20]. Moreover, another recent study reported that FOXO is an up regulator of IncRNA AF085935 thus promoting cancer survival [18].

\section{Conclusion}

We could conclude that chronic inflammation is a crucial element for cancer initiation and progression through subsequent activation of other molecular mediator that promotes cancer cell survival and proliferation; MSCs due to its anti-inflammatory effect could turn of this signaling cascade

\section{References}

1. Muscatell KA, Eisenberger NI, Dutcher JM, Cole SW, Bower JE. Links between inflammation, amygdala reactivity, and social support in breast cancer survivors. Brain Behav Immun. 2016;53:34-8. https://doi.org/10.1016/j.bbi.2015.09.008 PMid:26384778

2. Zhao S, Zhang Y, Zhang Q, Wang F, Zhang D. Toll-like receptors and prostate cancer. Front Immunol. 2014;5:352. https://doi. org/10.3389/fimmu.2014.00352

PMid:25101092

3. Wang X, Li X, Zhang X, Zang L, Yang H, Zhao W, et al. Tolllike receptor 4-induced inflammatory responses contribute to the tumor-associated macrophages formation and infiltration in patients with diffuse large B-cell lymphoma. Ann Diagn Pathol 2015;19(4):232-8. https://doi.org/10.1016/j. anndiagpath.2015.04.008

PMid:26071054

4. Dabagh-Gorjani F, Anvari F, Zolghadri J, Kamali-Sarvestani E, Gharesi-Fard B. Differences in the expression of TLRs and inflammatory cytokines in pre-eclamptic compared with healthy pregnant women. Iran J Immunol. 2014;11(4):233-45. https:// doi.org/10.1016/j.placenta.2009.11.004

PMid:25549591

5. Matijevic T, Pavelic J. Toll-like receptors: Cost or benefit for cancer? Curr Pharm Des 2010;16(9):1081-90. https://doi. org/10.2174/138161210790963779

PMid:20030618

6. Sabry D, Mostafa A, Hassouna A. Breast carcinoma is a multifactorial disease involving FOXN3, SINA3 and NEAT through repression of GATA3 and TJP. J Thorac Dis. 2018;10(3):1167-71. https://doi.org/10.21037/jtd.2018.02.65 


\section{PMid:29707264}

7. Zhao Y, Guo Q, Chen J, Hu J, Wang S, Sun Y. Role of long non-coding RNA HULC in cell proliferation, apoptosis and tumor metastasis of gastric cancer: A clinical and in vitro investigation. Oncol Rep. 2014;31(1):358-64. https://doi.org/10.3892/ or.2013.2850

\section{PMid:24247585}

8. Bolha L, Ravnik-Glavač M, Glavač D. Long noncoding RNAs as biomarkers in cancer. Dis Markers 2017;2017:7243968. https:// doi.org/10.1155/2017/7243968

9. Chulpanova DS, Kitaeva KV, Tazetdinova LG, James V, Rizvanov AA, Solovyeva VV. Application of mesenchymal stem cells for therapeutic agent delivery in anti-tumor treatment. Front Pharmacol. 2018;9:259. https://doi.org/10.3389/fphar.2018.00259 PMid:29615915

10. Weiss ML, Medicetty S, Bledsoe AR, Rachakatla RS, Choi M, Merchav S, et al. Human umbilical cord matrix stem cells: preliminary characterization and effect of transplantation in a rodent model of Parkinson's disease. Stem Cells. 2006;24(3):781-92. https://doi.org/10.1634/stemcells.2005-0330 PMid:16223852

11. Deshmukh SK, Srivastava SK, Dyess TP, Holliday NP, Singh AP Inflammation, immunosuppressive microenvironment and breast cancer: Opportunities for cancer prevention and therapy. Ann Transl Med. 2019;7(20):593. https://doi.org/10.21037/ atm.2019.09.68

PMid:31807574

12. Dethlefsen $C$, Højfeldt $G$, Hojman P. The role of intratumora and systemic IL-6 in breast cancer. Breast Cancer Res Treat. 2013;138(3):657-64. https://doi.org/10.1007/ s10549-013-2488-z PMid:23532539

13. Xia $\mathrm{Y}$, Shen $\mathrm{S}$, Verma IM. NF- $\kappa \mathrm{B}$, an active player in human cancers. Cancer Immunol Res. 2014;2(9):823-30. https://doi. org/10.1158/2326-6066.cir-14-0112

14. Scherzad A, Steber M, Gehrke T, Rak K, Froelich K,
Schendzielorz $\mathrm{P}$, et al. Human mesenchymal stem cells enhance cancer cell proliferation via IL-6 secretion and activation of ERK1/2. Int J Oncol. 2015;47(1):391-7. https://doi.org/10.3892/ ijo.2015.3009

PMid:25997536

15. Bhatelia K, Singh K, Singh R. TLRs: Linking inflammation and breast cancer. Cell Signal. 2014;26:2350-7. https://doi. org/10.1016/j.cellsig.2014.07.035

PMid:25093807

16. Luddy KA, Robertson-Tessi M, Tafreshi NK, Soliman H, Morse DL. The role of toll-like receptors in colorectal cancer progression: Evidence for epithelial to leucocytic transition. Front Immunol. 2014;5:429. https://doi.org/10.3389/fimmu.2014.00429 PMid:25368611

17. Bhattacharya D, Yusuf $N$. Expression of toll-like receptors on breast tumors: Taking a toll on tumor microenvironment. Int J Breast Cancer 2012;2012:716564. https://doi. org/10.1155/2012/716564 PMid:22295250

18. Mostafa A, Ibrahim NE, Sabry D, Fathy W, Elkazaz AY. Insulinlike growth factor initiates hepatocellular carcinoma in chronic hepatitis $C$ virus patients through induction of long non-coding ribonucleic acids AF085935: Role of LncRNAAF085935 in HCC development. Open Access Maced J Med Sci. 2021;9:222-8. https://doi.org/10.3889/oamjms.2021.5909

19. Fan W, Morinaga H, Kim JJ, Bae E, Spann NJ, Heinz S, et al. FoxO1 regulates TIr4 inflammatory pathway signalling in macrophages. EMBO J. 2010;29(24):4223-36. https://doi. org/10.1038/emboj.2010.268 PMid:21045807

20. Ito Y, Daitoku H, Fukamizu A. Foxo1 increases pro-inflammatory gene expression by inducing C/EBPbeta in TNF-alpha-treated adipocytes. Biochem Biophys Res Commun. 2009;378(2):290-5. https://doi.org/10.1016/j.bbrc.2008.11.043

PMid:19026986 